\title{
Deoxofluorination of graphite oxide with sulfur tetrafluoride
}

\section{$\operatorname{AUTHOR}(\mathrm{S})$ :}

Yamamoto, Hiroki; Matsumoto, Kazuhiko; Matsuo, Yoshiaki; Sato, Yuta; Hagiwara, Rika

\section{CITATION:}

Yamamoto, Hiroki ...[et al]. Deoxofluorination of graphite oxide with sulfur tetrafluoride. Dalton Transactions 2020, 49(1): 47-56

\section{ISSUE DATE:}

2020-01-07

URL:

http://hdl.handle.net/2433/245206

\section{RIGHT:}

This is the accepted manuscript of the article, which has been published in final form at

https://doi.org/10.1039/c9dt03782a.; The full-text file will be made open to the public on 7 January 2021 in accordance with publisher's 'Terms and Conditions for Self-Archiving'.; この論文は出版社版でありません。引用の際には出版社版 をご確認ご利用ください。; This is not the published version. Please cite only the published version. 


\section{Deoxofluorination of graphite oxide with sulfur tetrafluoride}

\section{Hiroki Yamamoto ${ }^{1}$, Kazuhiko Matsumoto ${ }^{1,}{ }^{*}$, Yoshiaki Matsuo ${ }^{2}$, Yuta Sato ${ }^{3}$, Rika Hagiwara ${ }^{1}$}

${ }^{1}$ Graduate School of Energy Science, Kyoto University, Yoshida, Sakyo-ku, Kyoto 606-8501, Japan

${ }^{2}$ Graduate School of Engineering, University of Hyogo, 2167 Shosha, Himeji, Hyogo 6712280, Japan

${ }^{3}$ Nanomaterials Research Institute, National Institute of Advanced Industrial Science and Technology (AIST), 1-1-1 Higashi, Tsukuba, Ibaraki 305-8565, Japan

*Corresponding author. Tel: +81-75-753-4817. E-mail: k-matsumoto@energy.kyoto-u.ac.jp (K. Matsumoto)

$\dagger$ Electronic supplementary information (ESI) available: TEM image, EELS elemental mappings, EELS and EDS spectra, XRD patterns, IR spectrum, and XPS spectra. See DOI: $\operatorname{xxxXXXXXXx}$ 


\section{Abstract}

In this study, deoxofluorination of graphite oxide (GO) using sulfur tetrafluoride $\left(\mathrm{SF}_{4}\right)$ at a temperature below the decomposition temperature of GO $\left(\sim 200{ }^{\circ} \mathrm{C}\right)$ was investigated for the first time with and without $\mathrm{HF}$ catalysis. At $25{ }^{\circ} \mathrm{C}$, the reaction proceeds only at high $\mathrm{SF}_{4}$ pressures ( $\geq 8 \mathrm{~atm}$ ) when not catalyzed by HF, and at $1 \mathrm{~atm}$ of $\mathrm{SF}_{4}$ under the catalysis of $\mathrm{HF}$. The degree of fluorination increases at higher temperatures and $\mathrm{SF}_{4}$ pressures. Hydroxy and carbonyl groups are replaced by fluorine following this reaction, and $\mathrm{SF}_{4}$ and $\mathrm{SOF}_{2}$ are introduced into the product, while the epoxy groups did not react. $\mathrm{SF}_{4}$ and $\mathrm{SOF}_{2}$ in the products are removed by washing with water. The obtained product is less hygroscopic than pristine GO owing to the hydrophobicity of the fluorine atom. The interlayer separation of the product is increased after deoxofluorination despite the smaller size of fluorine than the sizes of the oxygen-containing functional groups. When compared with direct fluorination using elemental fluorine, deoxofluorination using $\mathrm{SF}_{4}$ has the advantages of high reactivity with hydroxy groups and the preservation of the carbon skeleton, and the reaction results in the formation of graphite oxyfluoride. 


\section{Introduction}

Introduction of fluorine into graphite is an important way to modify its properties because fluorine imparts various unique properties such as hydrophobicity and high thermal and chemical stability to graphite. ${ }^{1}$ Fluorine substitution has also been attracting the attention of many researchers as a method to open the band gap of graphene, which is a monolayer of graphite that is known as a zero-band-gap material. ${ }^{2-8}$ One of the most common fluorinated graphite materials is poly(carbon monofluoride), $(\mathrm{CF})_{n}$, obtained by the reaction of graphite with $\mathrm{F}_{2}$ gas at $600^{\circ} \mathrm{C} .^{1,9}$ This material is utilized as a lubricant and a positive electrode material of lithium primary batteries. ${ }^{1,10,11}$ The low-temperature reaction of graphite with $\mathrm{F}_{2}$ gas (350$400{ }^{\circ} \mathrm{C}$ ) results in a graphite fluoride with a low degree of fluorination, poly(dicarbon monofluoride), $\left(\mathrm{C}_{2} \mathrm{~F}\right)_{n \cdot}{ }^{1,9}$ Both $(\mathrm{CF})_{n}$ and $\left(\mathrm{C}_{2} \mathrm{~F}\right)_{n}$ are composed of layers with saturated $\mathrm{sp}^{3}$ hybridized fluorinated carbon frames; each layer of $(\mathrm{CF})_{n}$ has a carbon skeleton made of cyclohexane chairs, whereas $\left(\mathrm{C}_{2} \mathrm{~F}\right)_{n}$ has a double-decked layer formed by the connection of two carbon skeletons of cyclohexane chairs with a $\mathrm{C}-\mathrm{C}$ covalent bond. Another type of fluorinated graphite, $\mathrm{C}_{x} \mathrm{~F}$, is formed in the presence of catalytic fluoroacids such as $\mathrm{HF}$ and $\mathrm{IF}_{5}$ at room temperature or slightly elevated temperatures. ${ }^{12-18}$ The $\mathrm{C}_{x}$ F-type carbon fluoride has covalent $\mathrm{C}-\mathrm{F}$ bonds and the carbon skeleton is buckled at the $\mathrm{sp}^{3}$-hybridized carbon atoms bound to fluorine atoms. ${ }^{19,20}$ Partially fluorinated or surface fluorinated graphitic compounds are also widely known and are considered for some applications. ${ }^{21-23}$ 
The synthesis of fluorinated graphite has also been attempted using graphite oxide (GO) as the precursor. ${ }^{17,24-31}$ Although the structure of GO is not fully understood, it has oxygencontaining functional groups such as hydroxy, carbonyl, and epoxy groups attached to its carbon skeleton. ${ }^{32}$ These functional groups can be substituted with fluorine using fluorinating agents such as $\mathrm{F}_{2}$ and $\mathrm{HF}^{24-28}$ Although the fluorination of GO with pure $\mathrm{F}_{2}$ leads to a high degree of fluorination, the carbon skeleton is destroyed and the crystallinity of the product is lowered owing to the strong oxidizing power of $\mathrm{F}_{2}$ gas. ${ }^{25}$ Further, although $\mathrm{F}_{2}$ can be diluted with $\mathrm{N}_{2}$ to render the reaction milder and thus prevent the destruction of the carbon skeleton, the fluorination of hydroxy groups does not proceed as expected. ${ }^{24}$ Thus, it is difficult to optimize the fluorination of GO using $\mathrm{F}_{2}$. As for the fluorination of GO with hydrofluoric acid and gaseous $\mathrm{HF},{ }^{27,28}$ the reduction of graphene oxide occurs in addition to the fluorination of GO. Further, although attempts have been made to fluorinate $\mathrm{GO}$ using $\mathrm{IF}_{5}, \mathrm{IF}_{5}$ does not react with GO by itself, and the mixture of $\mathrm{F}_{2}, \mathrm{HF}$, and $\mathrm{IF}_{5}$ does not seem to facilitate the substitution of the oxygen-containing functional groups with fluorine (graphene oxide is also included here, as the definitions of graphene oxide and graphite oxide are ambiguous). ${ }^{31}$

In this study, we attempted to fluorinate GO using sulfur tetrafluoride ( $\left.\mathrm{SF}_{4}\right)$ as the fluorinating agent. Sulfur tetrafluoride has the ability to deoxofluorinate both inorganic and organic compounds, ${ }^{33,34}$ and is also used as a starting material of various deoxofluorinating agents such as DAST (Diethylaminosulfur Trifluoride) and Deoxofluor (Bis(2- 
methoxyethyl)aminosulfur Trifluoride). ${ }^{35}$ Sulfur tetrafluoride can be synthesized from inexpensive starting materials such as $\mathrm{S}, \mathrm{Cl}_{2}$, and $\mathrm{NaF}^{33,36}$ and its milder oxidation power than that of $F_{2}$ is expected to enable the fluorination of GO without the destruction of the carbon skeleton. Although there is a report on the fluorination of $\mathrm{GO}$ using $\mathrm{SF}_{4}$ at $800{ }^{\circ} \mathrm{C}$ along with the exfoliation of the graphene sheet to obtain fluorinated graphene, ${ }^{37}$ the fluorination of GO using $\mathrm{SF}_{4}$ below the decomposition temperature of $\mathrm{GO}\left(\approx 200^{\circ} \mathrm{C}\right)$ has not been explored. ${ }^{38}$ The decrease in the reaction temperature leads to a higher degree of fluorination without the exfoliation of the material, because the oxygen-containing functional groups are preserved until the fluorination of the carbon skeleton with $\mathrm{SF}_{4}$ occurs. Herein, the effects of $\mathrm{SF}_{4}$ pressure and reaction temperature on the reactivity and structures of the products are systematically investigated. Further, the catalytic activity of $\mathrm{HF}$ in the reaction of $\mathrm{GO}$ with $\mathrm{SF}_{4}$ is also examined, as HF was reported to function as a catalyst in fluorination of organic compounds using $\mathrm{SF}_{4} \cdot{ }^{34,39,40}$ The obtained products were characterized by spectroscopic and electron microscopy studies.

\section{Experimental}

\subsection{Apparatus and Materials}

Volatile materials were handled in a reaction line made of SS-316 stainless steel and tetrafluoroethylene-perfluoroalkylvinylether copolymer. ${ }^{41}$ Nonvolatile materials were handled 
under dry Ar in a glove box. A nickel reactor $(100 \mathrm{~mL})$ was used for reactions. Sulfur tetrafluoride (SynQuest Laboratories, 94\%) was used as received. The main impurity contained in $\mathrm{SF}_{4}$ was $\mathrm{SOF}_{2}$ which does not affect the present experiments. Anhydrous HF (Daikin Industries) was dried over $\mathrm{K}_{2} \mathrm{NiF}_{6}$ (Ozark-Mahoning Co.) before use. Graphite oxide was prepared by the Brodie method as described in a previous work using natural graphite (Ito Graphite Co., Ltd, Z-5F) as a precursor. ${ }^{42}$ The resulting product was dried at $100{ }^{\circ} \mathrm{C}$ for $1-2$ days under vacuum before use. Caution: $\mathrm{SF}_{4}$ and HF are hazardous, and must be carefully handled using appropriate protective gear with immediate access to appropriate treatment procedures in the event of accident or their contact with skin. ${ }^{43}$

\subsection{Reaction of $\mathrm{GO}$ with $\mathrm{SF}_{4}$}

The conditions of the reaction of GO with $\mathrm{SF}_{4}$ are summarized in Table 1. Graphite oxide was weighed and loaded in a nickel reactor $(100 \mathrm{~mL})$ under dry Ar. After the evacuation of Ar in the reactor, $\mathrm{SF}_{4}$ was introduced into the reaction line and was distilled onto GO by cooling the reactor with liquid nitrogen, followed by slowly warming up the reactor to the reaction temperature (25 or $150{ }^{\circ} \mathrm{C}$ ). After the reaction, the reactor was cooled to $25^{\circ} \mathrm{C}$ in the case of the reaction at $150{ }^{\circ} \mathrm{C}$, and volatile gases were removed by evacuation through a soda lime chemical trap at first and through a cold trap cooled by liquid nitrogen for $24 \mathrm{~h}$. 
Table 1 Conditions of the reaction between GO and $\mathrm{SF}_{4}$

\begin{tabular}{cccccc}
\hline Sample name & $\begin{array}{c}\text { GO } \\
\text { weight } \\
\text { / mg }\end{array}$ & $\begin{array}{c}\mathrm{SF}_{4} \\
\text { pressure* } \\
/ \text { atm }\end{array}$ & $\begin{array}{c}\text { Temp. } \\
/{ }^{\circ} \mathrm{C}\end{array}$ & $\begin{array}{c}\text { Reaction } \\
\text { time } \\
/ \mathrm{h}\end{array}$ & $\begin{array}{c}\text { Product } \\
\text { weight } \\
/ \mathrm{mg}\end{array}$ \\
\hline FGO-150-1 & 92 & 1 & 150 & 24 & 93 \\
FGO-25-5 & 167 & 5 & 25 & 72 & 167 \\
FGO-25-8 & 274 & 8 & 25 & 72 & 328 \\
FGO-25-10 & 329 & 10 & 25 & 72 & 388 \\
\hline *Pressure at $25^{\circ} \mathrm{C}$. & & & & &
\end{tabular}

\subsection{Reaction of $\mathrm{GO}$ with $\mathrm{SF}_{4}$ in the presence of $\mathrm{HF}$ catalyst}

Reaction conditions for the reaction of GO with $\mathrm{SF}_{4}$ in the presence of HF catalyst are shown in Table 2. The procedure was analogous to the reaction between $\mathrm{GO}$ and $\mathrm{SF}_{4}$, except for the introduction of gaseous HF onto GO after the distillation of $\mathrm{SF}_{4}$. The amount of HF was volumetrically measured and adjusted to be 0.5 atm at $25^{\circ} \mathrm{C}$ in the reactor.

The FGO-150-5-HF sample (see Table 2 for its condition) was purified by water-washing. The purified sample was dried at $100{ }^{\circ} \mathrm{C}$ under dynamic vacuum for 2 days. The final product is denoted as FGO-150-5-HF-W.

\subsection{Analysis}

Infrared (IR) spectra of solid samples were obtained with an ALPHA I spectrometer (Bruker 
Optics Laboratories, Inc.) by the single reflection attenuated total reflection method. Baseline correction was applied to the obtained spectra. The IR spectra of gaseous samples were recorded with an ALPHA II spectrometer (Bruker Optics Laboratories, Inc.) in the transmission mode using a gas cell with $\mathrm{AgCl}$ windows. Powder X-ray diffraction (XRD) patterns were obtained in a Bragg-Brentano geometry using a Smartlab diffractometer (Rigaku Corp., D-tex Ultra 250) equipped with a Si-strip high speed detector ( $\mathrm{Cu} \mathrm{K \alpha}$ radiation, 40 kV, $30 \mathrm{~mA})$. Airsensitive samples were loaded in an airtight cell with Be windows in the glove box. X-ray photoelectron spectra (XPS) were obtained with a JPS-9010 MC spectrometer (JEOL, Ltd., Mg $K \alpha$ radiation). Samples were placed on indium foil and introduced into the instrument using an airtight cell. The binding energy of each peak was adjusted based on the C 1s peak at 284.8 $\mathrm{eV}^{44}$ Thermal properties of the samples were evaluated using ThermoPlusEvo2 TG8120 at a temperature ramp rate of $5{ }^{\circ} \mathrm{C} \min ^{-1}$ in air. Transmission electron microscopy (TEM) and scanning TEM (STEM) analyses were performed using a JEM-2100F microscope (JEOL, Ltd.) operated at $60 \mathrm{kV}$. Elemental analysis was performed at the Elemental Analysis Center at the Institute for Chemical Research, Kyoto University. 
Table 2 Conditions of the reaction between $\mathrm{GO}$ and $\mathrm{SF}_{4}$ in the presence of $\mathrm{HF}$

\begin{tabular}{|c|c|c|c|c|c|c|}
\hline Sample name & $\begin{array}{c}\text { GO } \\
\text { weight } \\
\text { / mg }\end{array}$ & $\begin{array}{c}\mathrm{SF}_{4} \\
\text { pressure* } \\
\text { / atm }\end{array}$ & $\begin{array}{l}\text { Temp. } \\
/{ }^{\circ} \mathrm{C}\end{array}$ & $\begin{array}{c}\text { Reaction } \\
\text { time } \\
\text { / h }\end{array}$ & $\begin{array}{c}\text { HF } \\
\text { pressure* } \\
\text { / atm }\end{array}$ & $\begin{array}{c}\text { Product } \\
\text { weight } \\
\text { / mg }\end{array}$ \\
\hline FGO-25-1-HF & 91 & 1 & 25 & 24 & 0.5 & 95 \\
\hline FGO-100-1-HF & 89 & 1 & 100 & 24 & 0.5 & 94 \\
\hline FGO-150-1-HF & 90 & 1 & 150 & 24 & 0.5 & 96 \\
\hline FGO-150-5-HF** & 413 & 5 & 150 & 24 & 0.5 & 475 \\
\hline \multicolumn{7}{|c|}{$\begin{array}{l}\text { *Pressure at } 25^{\circ} \mathrm{C} .{ }^{*} * \text { The sample prepared in this condition followed by water-washing is } \\
\text { named FGO-150-5-HF-W. }\end{array}$} \\
\hline
\end{tabular}

\section{Results and discussion}

\subsection{Reaction of GO with $\mathrm{SF}_{4}$}

Fig. 1 shows the IR spectra of GO before and after its reaction with $\mathrm{SF}_{4}$ under different reaction conditions (temperature and $\mathrm{SF}_{4}$ pressure) (see Table 1 for the detailed reaction conditions and the designated names of the products). The reaction did not proceed at $1 \mathrm{~atm}$ of $\mathrm{SF}_{4}$ even when the temperature was increased to $150{ }^{\circ} \mathrm{C}$. As the thermal decomposition of GO starts at $\sim 200{ }^{\circ} \mathrm{C},{ }^{38}$ no further increase in temperature was made; instead, the $\mathrm{SF}_{4}$ pressure was increased to 5, 8 , and $10 \mathrm{~atm}$. In the case of reactions at $25^{\circ} \mathrm{C}$, changes in the IR spectra were observed at 8 and 10 atm of $\mathrm{SF}_{4}$; the absorption bands assigned to the $\mathrm{O}-\mathrm{H}$ stretching (3500 $\left.\mathrm{cm}^{-1}\right)$ and $\mathrm{C}-\mathrm{O}-\mathrm{H}$ bending $\left(1300 \mathrm{~cm}^{-1}\right)$ modes almost disappeared, and that assigned to the $\mathrm{C}=\mathrm{O}$ stretching mode $\left(1720 \mathrm{~cm}^{-1}\right)$ decreased, while a new absorption band assigned to the $\mathrm{C}-$ 
F stretching mode $\left(1220 \mathrm{~cm}^{-1}\right)$ appeared., ${ }^{1,45}$ These results indicate that the hydroxy and carbonyl groups on GO were successfully substituted with fluorine at high $\mathrm{SF}_{4}$ pressures. On the other hand, characteristic absorption bands assignable to those of solid $\mathrm{SF}_{4}$ and $\mathrm{SOF}_{2}$ appeared below $1400 \mathrm{~cm}^{-1}$, 46,47 indicating the presence of $\mathrm{SF}_{4}$ and $\mathrm{SOF}_{2}$ in the product even after prolonged evacuation. It has been postulated that alkoxysulfur trifluoride $\left(\mathrm{C}-\mathrm{O}-\mathrm{SF}_{3}\right)$ is formed as a byproduct, or as an intermediate in the reaction of $\mathrm{C}-\mathrm{OH}$ or $\mathrm{C}=\mathrm{O}$ with $\mathrm{SF}_{4} \cdot{ }^{33,34,48}$ In addition, several types of reactions that lead to $\mathrm{C}-\mathrm{O}-\mathrm{S}$ bonds are known to occur between $\mathrm{SF}_{4}$ and organic compounds with oxygen-based functional groups. ${ }^{49-51}$ However, absence of the S-O stretching band at $\sim 700 \mathrm{~cm}^{-1}$ in the IR spectra suggests that the formation of such species are highly improbable. ${ }^{52}$ With regard to the presence of $\mathrm{SF}_{4}$, a band corresponding to the antisymmetric vibration mode of $\mathrm{S}-\mathrm{F}_{\mathrm{ax} 2}\left(\mathrm{~F}_{\mathrm{ax}}\right.$ is the $\mathrm{F}$ atom at the axial position) was observed at $\sim 660 \mathrm{~cm}^{-1}$, at the same position as that for solid $\mathrm{SF}_{4}$, while that of gaseous $\mathrm{SF}_{4}$ appears at $\sim 730 \mathrm{~cm}^{-1} .46,53$ This observation indicates that $\mathrm{SF}_{4}$ is stabilized through the interaction of $F_{a x}$ with an electropositive site between the fluorinated GO layers. On the other hand, the fluorination does not proceed on the epoxy groups, as deduced by the unchanged intensity of the band corresponding to the $\mathrm{C}-\mathrm{O}$ stretching mode at $\sim 1040 \mathrm{~cm}^{-1} .{ }^{54}$ 


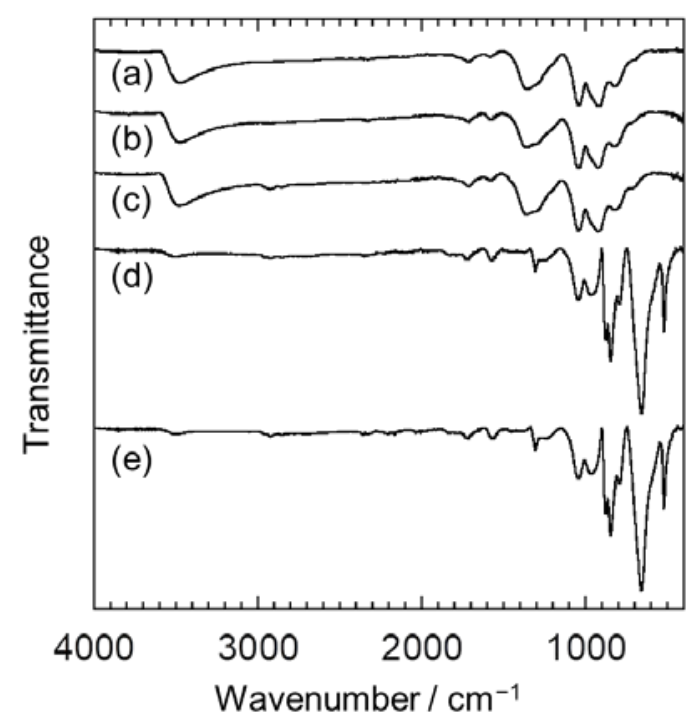

Fig. 1 Infrared spectra of GO before and after its reaction with $\mathrm{SF}_{4}$ : (a) pristine GO, (b) FGO150-1, (c) FGO-25-5, (d) FGO-25-8, and (e) FGO-25-10.

Fig. 2 shows the XRD patterns of GO before and after its reaction with $\mathrm{SF}_{4}$. Changes in the XRD patterns were observed for the products of reactions at 8 and $10 \mathrm{~atm}$ of $\mathrm{SF}_{4}$ and $25^{\circ} \mathrm{C}$. The 001 diffraction peak at $15.56^{\circ}$ corresponding to $d=5.70 \AA$ disappeared after the reaction, while two new broad peaks appeared at $12.9^{\circ}$ and $17.9^{\circ}$ corresponding to $d=6.9 \AA$ and $5.0 \AA$, respectively. These two peaks cannot be indexed to a one-layered compound, and the product is considered to consist of two different materials with low crystallinity. The repeating distance of $6.9 \AA$ can be attributed to the stacking of the carbon layer along the $c$-axis. The origin of the peak at $17.9^{\circ}$ is currently unknown, although it cannot be attributed to reduced GO because the corresponding interlayer distance is too large compared to that of reduced GO ( $\sim 4 \AA$ ) and an equivalent peak disappears after water-washing for the sample formed by the reaction with 5 
atm of $\mathrm{SF}_{4}$ in the presence of HF as described in the following section. ${ }^{27,28,30}$ Although the structure of the product obtained by the reaction of $\mathrm{GO}$ with $\mathrm{SF}_{4}(10 \mathrm{~atm})$ at $25{ }^{\circ} \mathrm{C}$ (denoted as FGO-25-10) was also characterized by electron diffraction (ED), the ED pattern only provided information about the graphite layer because of the preferred orientation of the material on the TEM grid (see Fig. S1, ESI). The energy dispersive X-ray spectroscopy (EDS) and electron energy loss spectroscopy (EELS) analyses of FGO-25-10 enabled the identification of only a small amount of sulfur ( $\mathrm{S} / \mathrm{C}=0.003$ for EDS and 0.009 for EELS) and a uniform distribution of all the elements (C, O, F, S) (see Fig. S1, ESI), indicating that the two different materials were distributed evenly in the product.
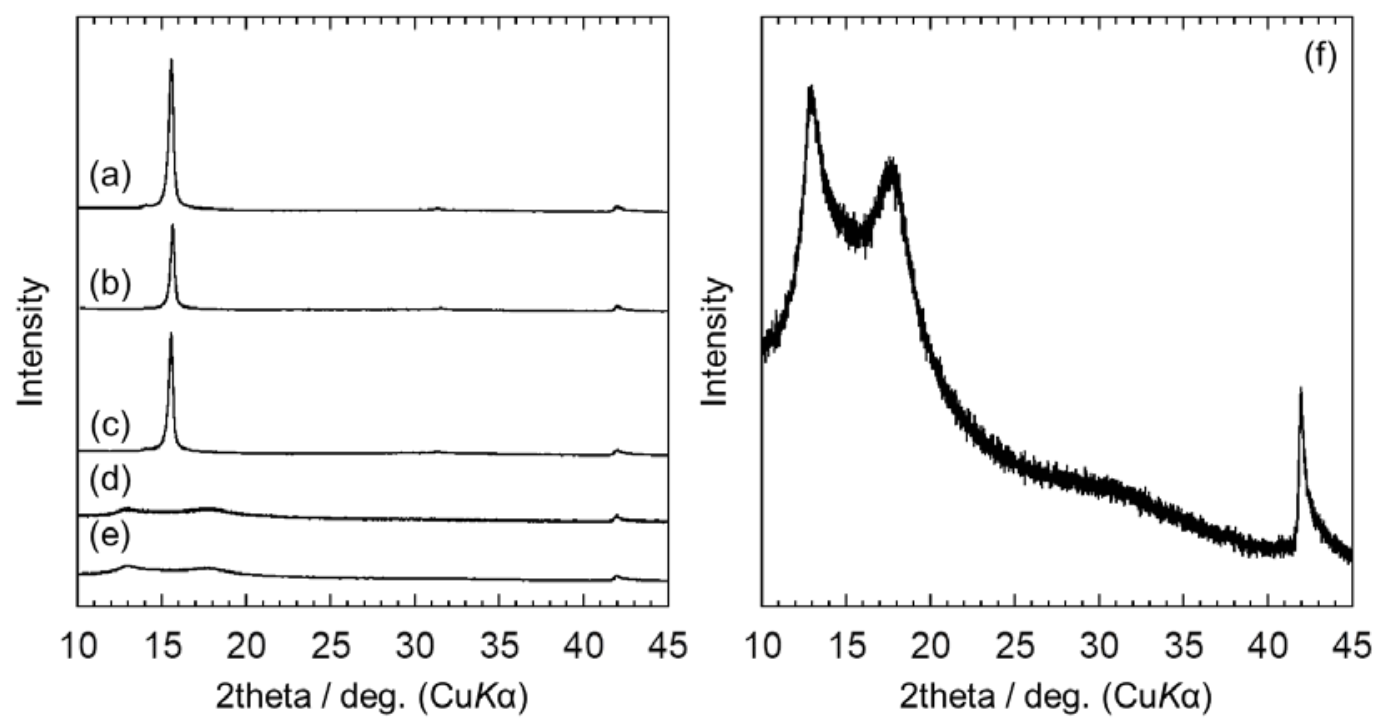

Fig. 2 X-ray diffraction patterns of GO before and after its reaction with $\mathrm{SF}_{4}$. (a) pristine GO, (b) FGO-150-1, (c) FGO-25-5, (d) FGO-25-8, and (e) FGO-25-10. (f) is the magnified pattern of FGO-25-10. 
The thermal behavior of GO also changed after its reaction with $\mathrm{SF}_{4}$. Fig. 3 shows the thermogravimetric (TG) curves and differential thermal analyses (DTA) of the pristine GO and FGO-25-10. As shown, the weight of the pristine GO started to decrease at $\sim 200{ }^{\circ} \mathrm{C}$ and a drastic weight loss occurred at $\sim 300^{\circ} \mathrm{C}$, accompanied by the heat emission detected by DTA. These are because of the expansion of GO caused by the gas evolved due to the decomposition of oxygen-containing functional groups. ${ }^{55}$ On the other hand, such an abrupt weight loss was not observed for FGO-25-10, indicating that the expansion of GO does not occur upon heating because of the elimination of oxygen-containing functional groups during the reaction. There are three possible decomposition paths (liberation of $\mathrm{SOF}_{2}$ and $\mathrm{SF}_{4}$, decomposition of oxygencontaining functional groups, and decomposition of C-F) for FGO-25-10. DTA of FGO-25-10 shows two exothermic peaks around $160^{\circ} \mathrm{C}$ and $260^{\circ} \mathrm{C}$. The latter peak could correspond to decomposition of oxygen-containing functional groups because the temperature is close to that of exothermic peak for GO. The former could derive from liberation of $\mathrm{SF}_{4}$ and $\mathrm{SOF}_{2}$ because decomposition of $\mathrm{C}-\mathrm{F}$ bonds occur over $500^{\circ} \mathrm{C}$ according to thermal behavior of fluorinated graphite. $^{56}$ 

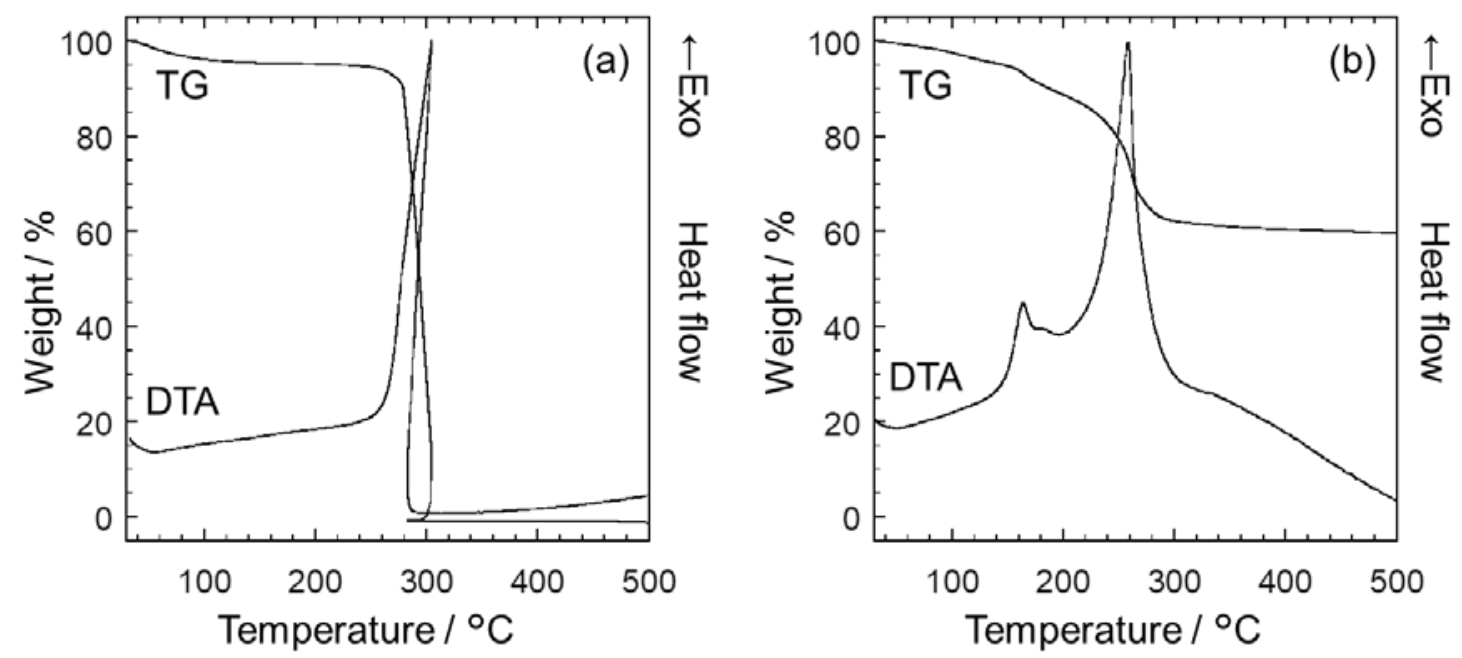

Fig. 3 Thermogravimetric curves and differential thermal analyses of (a) pristine GO and (b)

FGO-25-10. Pristine GO exothermically expanded at $\sim 300{ }^{\circ} \mathrm{C}$ and its weight reached zero.

\subsection{Reaction of GO with $\mathrm{SF}_{4}$ in the presence of $\mathrm{HF}$ catalyst}

As demonstrated in the previous section, a high $\mathrm{SF}_{4}$ pressure is required for the reaction of $\mathrm{GO}$ with $\mathrm{SF}_{4}$. As $\mathrm{HF}$ is known to catalyze the deoxofluorination reaction with $\mathrm{SF}_{4}$, we expected to facilitate the fluorination of GO with $\mathrm{SF}_{4}$ using $\mathrm{HF}$ as a catalyst. ${ }^{33}$ As a control reaction, GO was first reacted with $\mathrm{HF}$ in the absence of $\mathrm{SF}_{4}$ and no change in the XRD pattern following the reaction was confirmed (see Fig. S2, ESI, for the XRD pattern of the product obtained by the treatment of GO with $\mathrm{HF}(0.5 \mathrm{~atm})$ at $\left.150^{\circ} \mathrm{C}\right)$. The possible reasons for this result in contrast with the previous report on the reaction of graphene oxide with gaseous HF could be different experimental conditions such as the graphite powder used as the precursor, synthetic method of GO or graphene oxide, and fluorination method. ${ }^{28}$

Fig. 4 shows the IR spectra of GO before and after its reaction with $\mathrm{SF}_{4}$ in the presence of 
HF (see Table 2 for detailed reaction conditions). The intensity of the absorption band of the hydroxy group (3500 $\left.\mathrm{cm}^{-1}\right)$ decreased significantly, and that of carbonyl group $\left(1720 \mathrm{~cm}^{-1}\right)$ showed some decrease, which is confirmed in the XPS section below, accompanied by the appearance of the $\mathrm{C}-\mathrm{F}$ stretching mode $\left(1220 \mathrm{~cm}^{-1}\right)$, even for a reaction at $1 \mathrm{~atm}$ of $\mathrm{SF}_{4}$ and $25^{\circ} \mathrm{C}$ in the presence of $\mathrm{HF}$ as a catalyst. This is in contrast to the low reactivity of GO with $\mathrm{SF}_{4}$ in the absence of $\mathrm{HF}$ (no reaction occurs at $1 \mathrm{~atm}$ and $150{ }^{\circ} \mathrm{C}$, see above) and confirms the catalytic activity of HF in this reaction. Table 3 presents the results of the elemental analysis of the products of the reaction of GO with $\mathrm{SF}_{4}$ in the presence of $\mathrm{HF}$. The $\mathrm{F} / \mathrm{C}$ molar ratio increased slightly upon increasing the reaction temperature, from a value of 0.09 at $25{ }^{\circ} \mathrm{C}$ to 0.10 at $100{ }^{\circ} \mathrm{C}$, and to 0.13 at $150{ }^{\circ} \mathrm{C}$ under the same $\mathrm{SF}_{4}$ pressure of 1 atm although some fluorine wt\% could come from $\mathrm{SF}_{4}$ and $\mathrm{SOF}_{2}$ in the samples. An increase in the $\mathrm{SF}_{4}$ pressure from 1 to $5 \mathrm{~atm}$ led to a further increase in the $\mathrm{F} / \mathrm{C}$ ratio to 0.17 at $150{ }^{\circ} \mathrm{C}$. On the other hand, characteristic absorption bands appeared below $1400 \mathrm{~cm}^{-1}$ as is the case of the reaction between $\mathrm{GO}$ and $\mathrm{SF}_{4}$ in the absence of HF (see Fig. 1). Although the intensity ratio of bands assigned to $\mathrm{SF}_{4}$ to those assigned to $\mathrm{SOF}_{2}$ is small for the products of the reaction at 1 atm of $\mathrm{SF}_{4}$, the ratio increased upon increasing the $\mathrm{SF}_{4}$ pressure from 1 to 5 atm (Fig. 4 (f) and (g)). This result indicates that the ratio of $\mathrm{SF}_{4}$ to $\mathrm{SOF}_{2}$ introduced into the product depends on the $\mathrm{SF}_{4}$ pressure. On the other hand, the carbon skeleton does not appear to be destructed because no band corresponding to $-\mathrm{CF}-\mathrm{CF}_{3}$ at $\sim 1900 \mathrm{~cm}^{-1}$, which generally appears upon the destruction, is 
observed in the IR spectrum. ${ }^{25}$ This inference is also supported by the absence of fluorocarbon gases such as $\mathrm{CF}_{4}$ in the residual gas after the reaction of $\mathrm{GO}$ with $\mathrm{SF}_{4}(5 \mathrm{~atm})$ in the presence of HF (see Fig. S3).
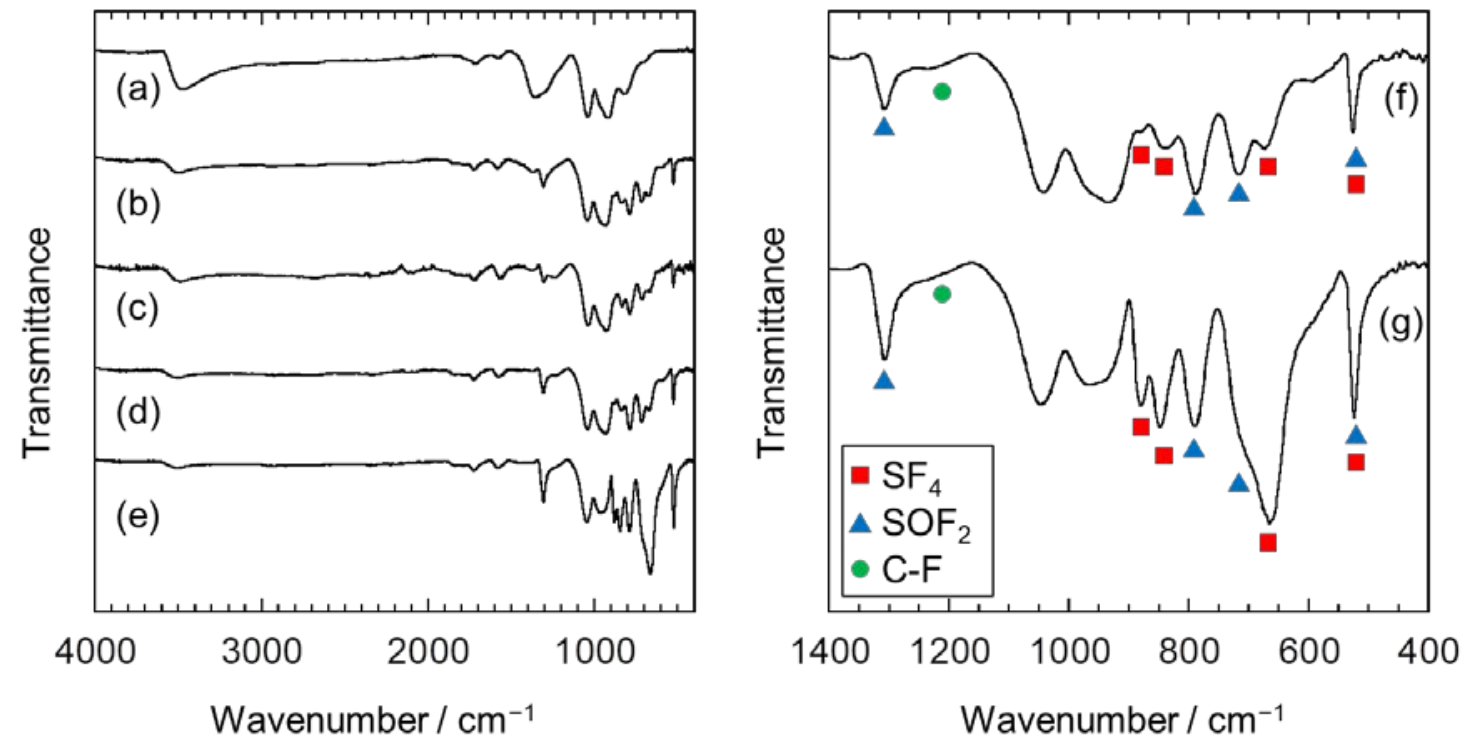

Fig. 4 Infrared spectra of GO before and after its reaction with $\mathrm{SF}_{4}$ in the presence of HF. (a) pristine GO, (b) FGO-25-1-HF, (c) FGO-100-1-HF, (d) FGO-150-1-HF, and (e) FGO-150-5HF. (f) and (g) show the magnified spectra of FGO-150-1-HF and FGO-150-5-HF (400-1400 $\mathrm{cm}^{-1}$ ), respectively. 
Table 3 Results of the elemental analysis of the products of the reaction between GO and $\mathrm{SF}_{4}$ in the presence and absence of HF

\begin{tabular}{|c|c|c|c|c|c|c|c|}
\hline \multirow{2}{*}{ Samples } & \multicolumn{5}{|c|}{ Elements/ wt\% } & \multicolumn{2}{|c|}{ Atomic ratios } \\
\hline & $\mathrm{C}$ & $\mathrm{H}$ & $\mathrm{F}$ & $\mathrm{S}$ & $\mathrm{O}^{*}$ & $\mathrm{~F} / \mathrm{C}^{* *}$ & $\mathrm{O} / \mathrm{C}$ \\
\hline GO & 59.4 & 1.3 & - & - & 39.3 & - & 0.50 \\
\hline FGO-25-10 & 56.6 & 0.2 & 11.5 & 3.9 & 27.8 & 0.13 & 0.37 \\
\hline FGO-25-1-HF & 62.6 & 0.4 & 9.1 & 1.4 & 26.5 & 0.09 & 0.32 \\
\hline FGO-100-1-HF & 62.6 & 0.4 & 10.2 & 1.7 & 25.1 & 0.10 & 0.30 \\
\hline FGO-150-1-HF & 61.9 & 0.2 & 12.5 & 1.9 & 23.5 & 0.13 & 0.28 \\
\hline FGO-150-5-HF & 57.1 & 0.4 & 15.5 & 4.1 & 22.9 & 0.17 & 0.30 \\
\hline FGO-150-5-HF-W & 60.8 & 0.5 & 9.9 & 1.9 & 26.9 & 0.10 & 0.33 \\
\hline
\end{tabular}

Fig. 5 shows the XRD patterns of GO before and after its reaction with $\mathrm{SF}_{4}$ in the presence of HF. A new diffraction peak appears at $\sim 14.9^{\circ}$ after the reaction at $25{ }^{\circ} \mathrm{C}$, but the 001 diffraction peak of pristine $\mathrm{GO}$ at $15.56^{\circ}$ corresponding to $d=5.70 \AA$ still remains. The 001 diffraction peak of GO disappears after reactions at 100 and $150{ }^{\circ} \mathrm{C}$. The peak that appeared newly at $14.9^{\circ}$ corresponds to $d=5.94 \AA$ and is accompanied by a weak shoulder at a higher angle. On the other hand, two broad peaks appear at $13.6^{\circ}$ and $17.2^{\circ}$, corresponding to $d=6.5$ 
and $5.2 \AA$, respectively, upon increasing the $\mathrm{SF}_{4}$ pressure from 1 to 5 atm as in the case of the reaction of GO at a high $\mathrm{SF}_{4}$ pressure in the absence of HF (see Fig. 2 (d), (e), and (f)). These observations suggest that these two broad peaks are characteristic for the products of GO treated at high $\mathrm{SF}_{4}$ pressures and suggest the incorporation of $\mathrm{SF}_{4}$ and $\mathrm{SOF}_{2}$ molecules in the material.

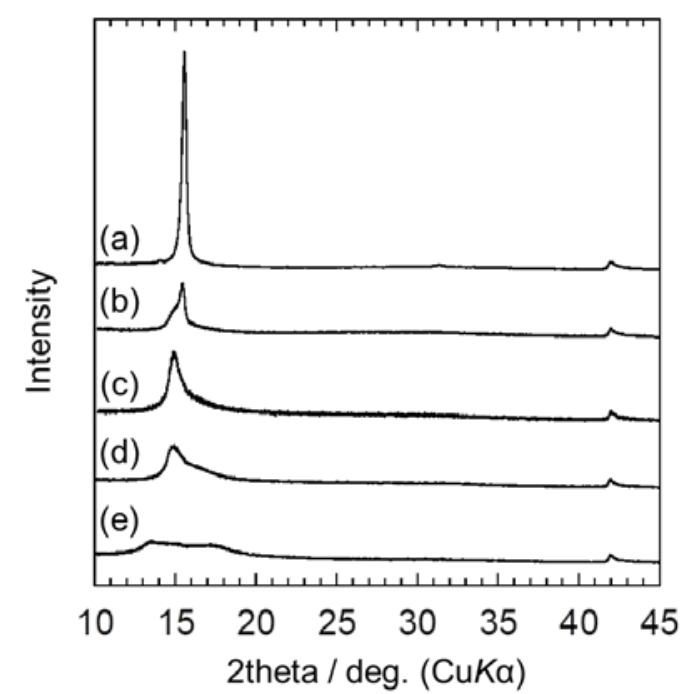

Fig. $5 \mathrm{X}$-ray diffraction patterns of GO before and after its reaction with $\mathrm{SF}_{4}$ in the presence of HF. (a) pristine GO, (b) FGO-25-1-HF, (c) FGO-100-1-HF, (d) FGO-150-1-HF, and (e) FGO150-5-HF.

Fig. 6 shows the XPS spectra of GO before and after its reaction with $\mathrm{SF}_{4}(5 \mathrm{~atm})$ at $150{ }^{\circ} \mathrm{C}$ in the presence of HF (denoted as FGO-150-5-HF) in the C 1s region. Dotted lines show peak positions of carbon atoms with different bonding states (C-C (284.8 eV), $\underline{C}-\mathrm{CF}(285.4 \mathrm{eV})$, $\mathrm{C}-\mathrm{O}(286.2 \mathrm{eV}), \mathrm{C}=\mathrm{O}(287.8 \mathrm{eV}), \mathrm{C}-\underline{\mathrm{C} F}(288.5 \mathrm{eV})$, and $\mathrm{O}-\mathrm{C}=\mathrm{O}(289.0 \mathrm{eV}))$ according to 
references. ${ }^{24,44}$ Comparison of the two spectra indicates decreases in the intensities of the peaks assigned to $\mathrm{C}-\mathrm{O}$ and $\mathrm{C}=\mathrm{O}$ after the reaction of $\mathrm{GO}$ with $\mathrm{SF}_{4}$. On the other hand, peaks assigned to $\underline{\mathrm{C}}-\mathrm{CF}$ and $\mathrm{C}-\underline{\mathrm{C} F}$ are observed in the spectrum of FGO-150-5-HF, and fluorine is detected by elemental analysis (see Table 3). The larger binding energy of the $\mathrm{C} 1$ s peak of $\underline{\mathrm{C}}-\mathrm{CF}$ than that of $\mathrm{C}-\mathrm{C}$ was observed in the XPS spectra of $\mathrm{C}_{x} \mathrm{~F},{ }^{57}$ which is explained by hyperconjugation involving $\mathrm{C}-\mathrm{F}$ and $\mathrm{C}-\mathrm{C}$ bonds. An electron is donated from an $\mathrm{sp}^{2}$ carbon to the antibonding $\sigma^{*}$ orbital of C-F bonds, which also leads to a higher chemical shift of $\mathrm{F}$ in the ${ }^{19} \mathrm{~F}$ NMR spectrum. ${ }^{16,20,58}$ This can also explain the lower binding energy of the C 1s peak of C-C F (288.5 $\mathrm{eV})$ than that of $\mathrm{C}-\mathrm{F}\left(290 \mathrm{eV}\right.$, observed in $(\mathrm{CF})_{n}$, in which carbon atoms are not adjacent to $\mathrm{sp}^{2}$ carbons). ${ }^{15}$ There seems to be a peak at $~ 290 \mathrm{eV}$ in the spectrum of FGO-150-5-HF, which is discussed in the following section.
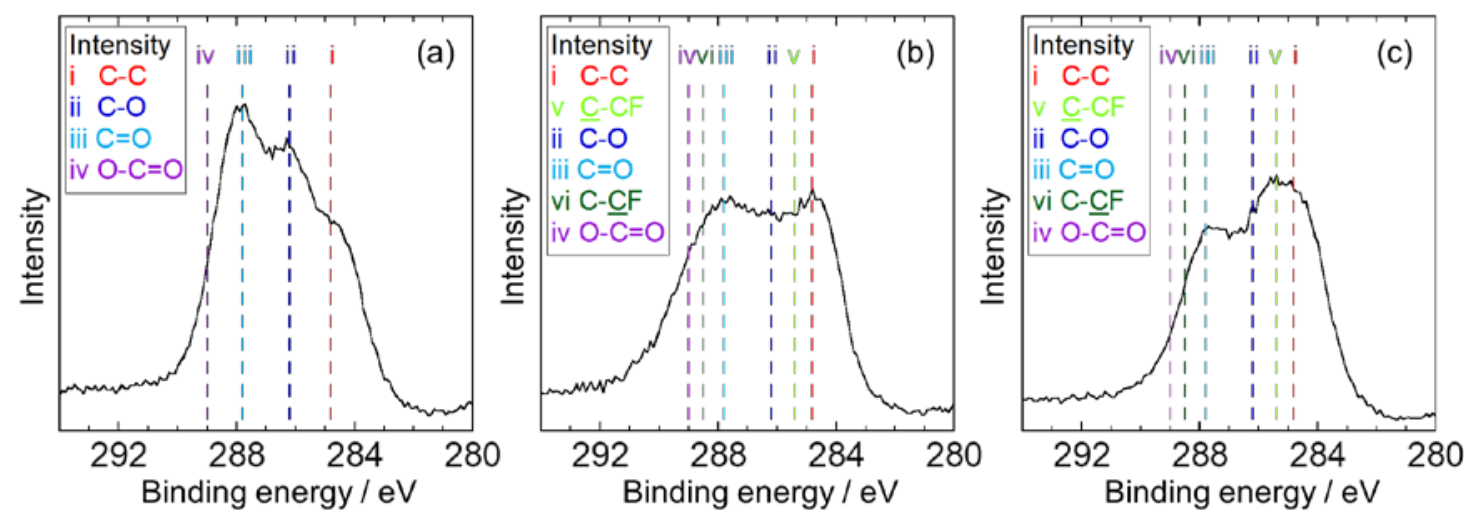

Fig. 6 X-ray photoelectron spectra (C 1s) of (a) pristine GO, (b) FGO-150-5-HF, and (c) FGO150-5-HF-W. 
As mentioned above, the presence of $\mathrm{SF}_{4}$ and $\mathrm{SOF}_{2}$ in the products is indicated after the reactions. Therefore, FGO-150-5-HF, which is the most fluorinated product, was purified by washing with water to remove $\mathrm{SF}_{4}$ and $\mathrm{SOF}_{2}$, followed by the evacuation of volatiles at $100{ }^{\circ} \mathrm{C}$ for 2 days. The obtained product is denoted as FGO-150-5-HF-W.

Fig. 7 shows the IR spectra of pristine GO, FGO-150-5-HF, and FGO-150-5-HF-W. The absorption bands assigned to $\mathrm{SF}_{4}$ and $\mathrm{SOF}_{2}$ disappear after water-washing, and the intensity of the C-F stretching band at $\sim 1220 \mathrm{~cm}^{-1}$ becomes stronger. This may be due to further fluorination of $\mathrm{GO}_{\text {by }} \mathrm{SF}_{4}$ in the presence of water, resulting in the relative increase in the $\mathrm{C}-$ F bond on the surface of the material, as IR spectroscopy mainly detects surface species. This hypothesis of further fluorination is further validated by the XPS of FGO-150-5-HF-W in the C 1s region shown in Fig. 6 (c), wherein the intensity of the peak at $\sim 285.4 \mathrm{eV}$ assigned to $\underline{\mathrm{C}}-$ CF increases after water-washing. On the other hand, the peak at $290 \mathrm{eV}$ observed in the spectrum of FGO-150-5-HF disappeared after water-washing (not assigned in the spectrum). Although a peak assigned to C-F is observed at $\sim 290 \mathrm{eV}$ in $(\mathrm{CF}){ }_{n},{ }^{15} \mathrm{C}-\mathrm{F}$ bonds should be stable in water. Therefore, it is not attributed to $\mathrm{C}-\mathrm{F}$. Although the IR bands assigned to $\mathrm{SF}_{4}$ and $\mathrm{SOF}_{2}$ in the IR spectra disappeared after water-washing, it is not clear whether the peaks are related to their presence. 


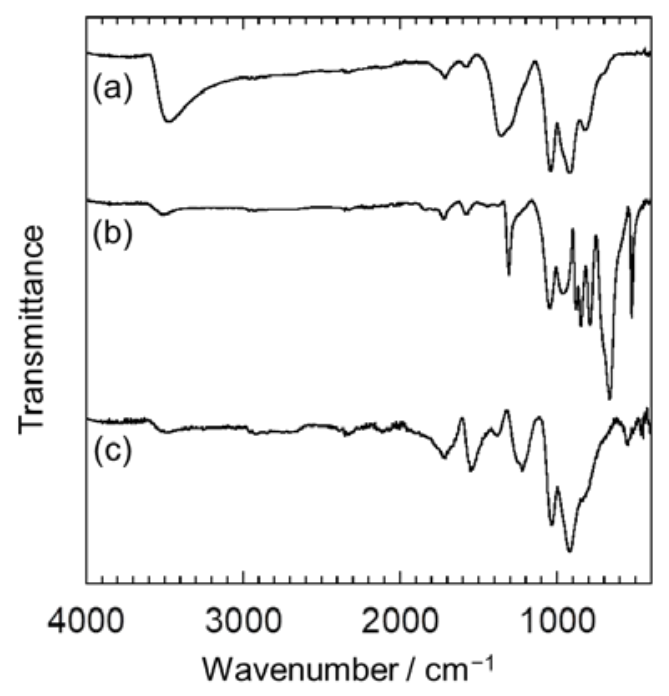

Fig. 7 Infrared spectra of (a) pristine GO, (b) FGO-150-5-HF, and (c) FGO-150-5-HF-W.

Fig. 8 shows the XRD patterns of pristine GO and FGO-150-5-HF-W. The two broad peaks observed in the pattern of FGO-150-5-HF (Fig. 5 (e)) disappeared in the pattern of FGO150-5-HF-W, and a new relatively sharp peak appeared at $15.20^{\circ}$ corresponding to $d=5.83 \AA$, which suggests a slightly longer layer separation than that of the pristine GO (5.70 $)$ ). This result is in contrast to the case for the reaction of graphene oxide with DAST, where the layer separation corresponding to the 001 diffraction peak becomes shorter after the treatment, suggesting the reduction of graphene oxide. ${ }^{30}$

Pristine GO and FGO-150-5-HF-W were exposed to air to investigate their reactivity with moisture. The XRD patterns in Fig. 8 (c, d) show that the 001 diffraction peak of pristine GO shifts to a lower angle from $15.56^{\circ}(5.70 \AA)$ to $14.02^{\circ}(6.32 \AA)$ after 1 -h exposure to the air. On the other hand, FGO-150-5-HF-W exhibits only a slight shift (from $15.20^{\circ}$ (5.83 $\AA$ ) to 
$\left.15.08^{\circ}(5.87 \AA)\right)$ even after 24 -h exposure to the air. This result demonstrates that the hygroscopicity of FGO-150-5-HF-W is lowered significantly compared to that of GO owing to the introduction of fluorine and the elimination of oxygen-containing functional groups such as $\mathrm{OH}$ and $\mathrm{C}=\mathrm{O}$ groups. The $\mathrm{F} / \mathrm{C}$ ratio of 0.10 for FGO-150-5-HF-W (Table 3) is larger than that of the product of the reaction between graphene oxide and $\mathrm{SF}_{4}$ at $800{ }^{\circ} \mathrm{C}(\mathrm{F} / \mathrm{C}=0.03$, including sulfur-containing species), ${ }^{37}$ but is slightly smaller than that of FGO-150-5-HF because of the elimination of $\mathrm{SF}_{4}$ and $\mathrm{SOF}_{2}$.
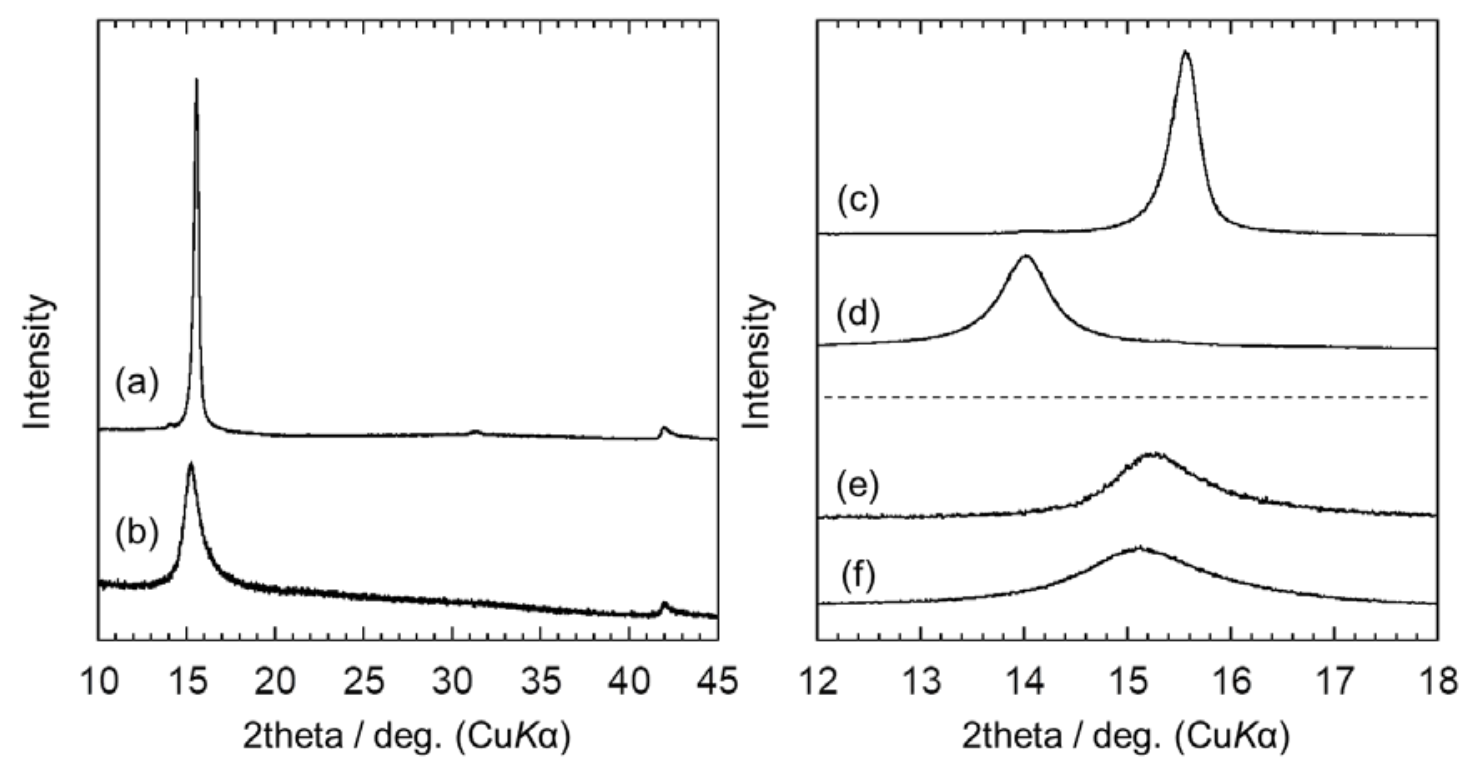

Fig. 8 X-ray diffraction patterns of (a) pristine GO and (b) FGO-150-5-HF-W. (c) and (e) are the magnified patterns of pristine GO and FGO-150-5-HF-W, respectively. (d) and (f) are XRD patterns collected after placing pristine GO in the air for $1 \mathrm{~h}$ and FGO-150-5-HF-W in air for $24 \mathrm{~h}$, respectively. 


\subsection{Summary of the deoxofluorination of GO}

Deoxofluorination reactions of the present study are summarized in Fig. 10. The reactivity differed significantly depending on the temperature and pressure of $\mathrm{SF}_{4}$, and the presence or absence of HF catalyst. As compared with the fluorination of GO using pure $\mathrm{F}_{2}$, fluorination using $\mathrm{SF}_{4}$ has the advantage of the preservation of the carbon skeleton. The carbon skeleton of GO is destroyed owing to the strong oxidation power of $F_{2}$ gas during the deoxofluorination using pure $\mathrm{F}_{2}$ gas, ${ }^{25}$ while $\mathrm{SF}_{4}$ does not affect the carbon skeleton because of its weak oxidation power. This is confirmed by the absence of $\mathrm{CF}_{4}$ in the residual gas of FGO-150-5-HF after the reaction (Fig. S3) and $-\mathrm{CF}-\mathrm{CF}_{3}$ and $\mathrm{CF}_{3}$ groups in the products (Fig. 1, 4, and 6). ${ }^{27}$ Although fluorination of $\mathrm{GO}$ with diluted $\mathrm{F}_{2}$ gas occurs more mildly than that with pure $\mathrm{F}_{2}$ gas, the fluorination of the hydroxy group is sluggish. ${ }^{24}$ In contrast, $\mathrm{SF}_{4}$ can effectively deoxofluorinate the hydroxy groups without destroying the carbon skeleton.

With regard to the structures of the fluorinated products, their interlayer distance is larger than that of pristine GO. The same results were obtained for the fluorination of GO with $\mathrm{F}_{2}{ }^{24,25}$ However, this contradicts the fact that the fluorine atom is smaller in size than the oxygencontaining functional groups. This phenomenon can be interpreted as follows (see the illustration in Fig. 9). Graphite layers with oxygen-containing groups in GO are highly polar and interact with the adjacent layers. A typical interaction is the hydrogen bonding between the hydrogen atom on the hydroxy group and the oxygen atom of another hydroxy group or 
epoxy group..$^{59,60} \mathrm{~F}$ atoms attached to the carbon skeleton only weakly interact with other atoms owing to the small polarizability of $\mathrm{F}$ and the strong covalency of the C-F bond, which results in the increase in the interlayer distance of the fluorinated product. The interlayer distance of $\mathrm{C}_{x} \mathrm{~F}$-type fluorinated graphite (see Introduction for $\mathrm{C}_{x} \mathrm{~F}$-type fluorinated graphite) prepared by the reaction of graphite with $\mathrm{F}_{2}$ in the presence of HF reached $5.84 \AA$ for the composition of $\mathrm{C}_{2.3 \mathrm{~F}}{ }^{15}$ which is already larger than that of pristine GO (5.70 $\left.\AA\right)$. The lower hygroscopicity of FGO-150-5-HF-W compared to that of pristine GO also supports this structural model. The lower crystallinity of the fluorinated product compared with that of pristine GO can be also explained by the weak interaction between the layers of the former.

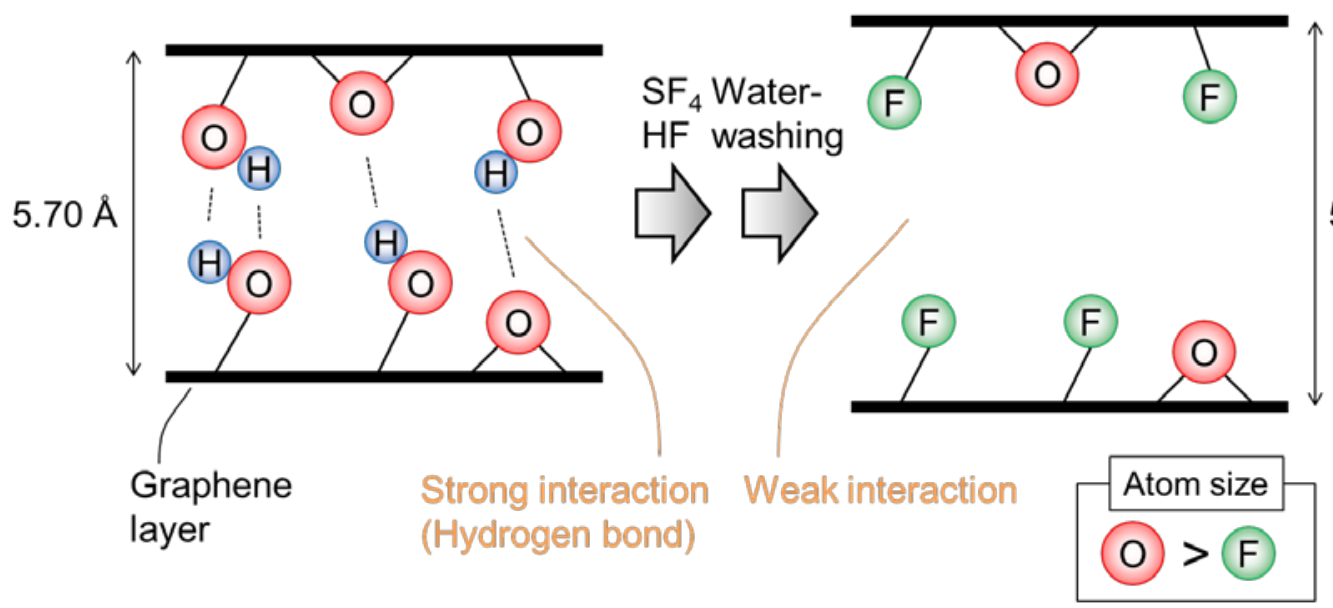

Fig. 9 Schematic illustration of the deoxofluorination of GO using $\mathrm{SF}_{4}$. The interlayer distance increases after fluorination owing to the weak interaction, despite the smaller size of $\mathrm{F}$ compared to that of $\mathrm{O}$. 


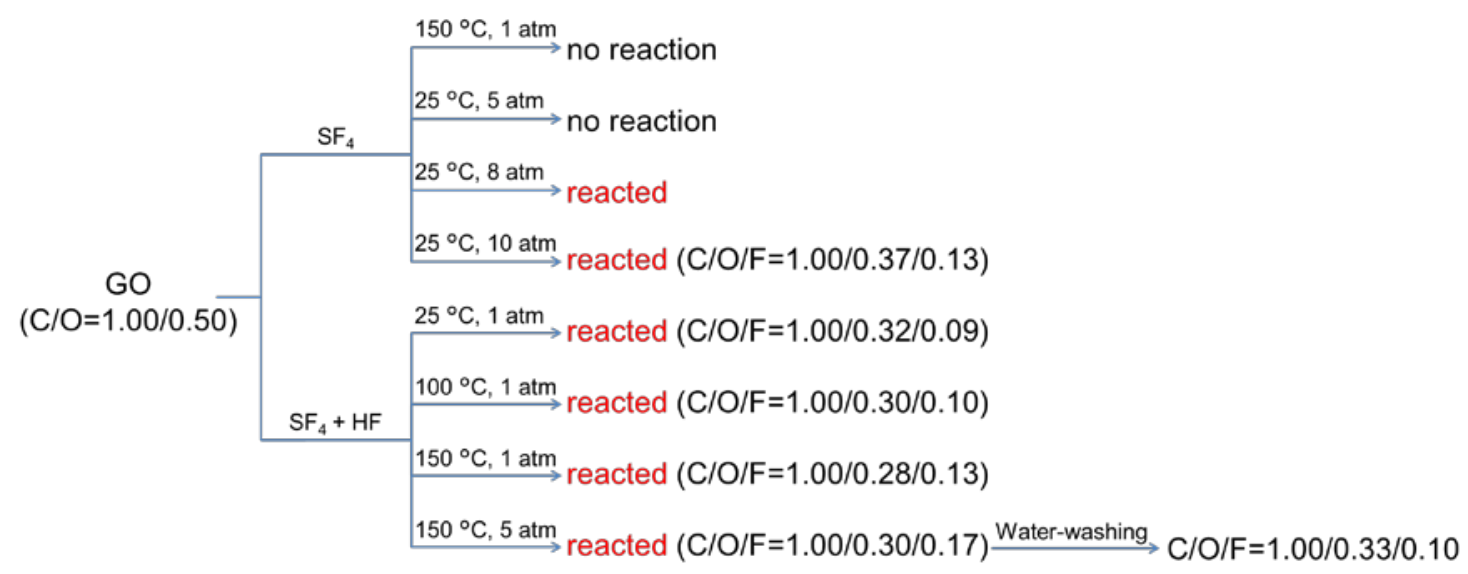

Fig. 10 Summary of reactions in the present study. The molar ratios of C/O/F were obtained by elemental analysis (Table 3).

\section{Conclusion}

The reactivity of GO with $\mathrm{SF}_{4}$ below the decomposition temperature of GO and the structural characterization of the products were presented. The deoxofluorination of GO proceeded only under high $\mathrm{SF}_{4}$ pressures $(\geq 8 \mathrm{~atm})$ at $25{ }^{\circ} \mathrm{C}$. However, $\mathrm{SF}_{4}$ and $\mathrm{SOF}_{2}$ were introduced into deoxofluorinated GO under these conditions. The fluorinated product did not expand upon heating, in contrast to pristine GO that expands at $\sim 300^{\circ} \mathrm{C}$. Substitution of oxygen-containing groups with fluorine is considered to suppress the release of gaseous species at high temperatures. Disorder in the stacking structure might also cause such behavior. The reaction was catalyzed by HF, and in the presence of HF, the structural change was confirmed even at 1 atm of $\mathrm{SF}_{4}$ at $25{ }^{\circ} \mathrm{C}$, although $\mathrm{SF}_{4}$ and $\mathrm{SOF}_{2}$ were also introduced into the product. This reaction was further accelerated at 100 and $150{ }^{\circ} \mathrm{C}$, and increasing the $\mathrm{SF}_{4}$ pressure to 5 atm 
led to the introduction of more $\mathrm{SF}_{4}$ in the product. The $\mathrm{SF}_{4}$ and $\mathrm{SOF}_{2}$ species in the products were eliminated by washing with water; water-washing was accompanied by further fluorination, and the obtained product was confirmed to be less hygroscopic compared to pristine GO owing to the hydrophobicity of the fluorine atom. The F/C ratio of the product after water-washing was found to be 0.10 , and the final product is regarded as graphite oxyfluoride because the graphite layer in the product was found to contain both fluorine and oxygen $(\mathrm{O} / \mathrm{C} \approx 0.3)$. Unlike $\mathrm{F}_{2}$ gas, $\mathrm{SF}_{4}$ can fluorinate $\mathrm{GO}$ without destroying the carbon skeleton, and the reduction of GO was not observed unlike in the cases of fluorination using HF and DAST. Further optimization of the reaction condition or the introduction of a more effective catalyst could lead to highly fluorinated graphite materials. Exfoliation of the fluorinated GO is an interesting future work in comparison with fluorinated graphene prepared by fluorination of graphene with diluted $\mathrm{F}_{2}{ }^{6-8}$

\section{Acknowledgements}

This work was financially supported by JSPS KAKENHI Grant Number 17K14544 (K. M.) and JSPS KAKENHI Grant Number 19K05223 (Y. S.). 


\section{References}

1. $\quad$ N. Watanabe, T. Nakajima and H. Touhara, Graphite Fluorides, Elsevier, Amsterdam, 1988.

2. $\quad$ R. R. Nair, W. Ren, R. Jalil, I. Riaz, V. G. Kravets, L. Britnell, P. Blake, F. Schedin, A. S. Mayorov, S. Yuan, M. I. Katsnelson, H. M. Cheng, W. Strupinski, L. G. Bulusheva, A. V. Okotrub, I. V. Grigorieva, A. N. Grigorenko, K. S. Novoselov and A. K. Geim, Small, 2010, 6, 2877-2884.

3. K.-J. Jeon, Z. Lee, E. Pollak, L. Moreschini, A. Bostwick, C.-M. Park, R. Mendelsberg, V. Radmilovic, R. Kostecki, T. J. Richardson and E. Rotenberg, ACS Nano, 2011, 5, 1042-1046.

4. J. T. Robinson, J. S. Burgess, C. E. Junkermeier, S. C. Badescu, T. L. Reinecke, F. K. Perkins, M. K. Zalalutdniov, J. W. Baldwin, J. C. Culbertson, P. E. Sheehan and E. S. Snow, Nano Lett., 2010, 10, 30013005.

5. R. Zbořil, F. Karlický, A. B. Bourlinos, T. A. Steriotis, A. K. Stubos, V. Georgakilas, K. Šafářová, D. Jančík, C. Trapalis and M. Otyepka, Small, 2010, 6, 2885-2891.

6. V. Mazánek, A. Libánská, J. Šturala, D. Bouša, D. Sedmidubský, M. Pumera, Z. Janoušek, J. Plutnar and Z. Sofer, Chemistry - A European Journal, 2017, 23, 1956-1964.

7. V. Mazánek, L. Pavlikova, P. Marvan, J. Plutnar, M. Pumera and Z. Sofer, Applied Materials Today, 2019, 15, 343-349.

8. S. Hermanová, D. Bouša, V. Mazánek, D. Sedmidubský, J. Plutnar, M. Pumera and Z. Sofer, Chemistry - A European Journal, 2018, 24, 16833-16839.

9. $\quad$ Y. Sato, K. Itoh, R. Hagiwara, T. Fukunaga and Y. Ito, Carbon, 2004, 42, 2897-2903.

10. R. L. Fusaro, Wear, 1979, 53, 303-323.

11. H. Touhara, H. Fujimoto, N. Watanabe and A. Tressaud, Solid State Ionics, 1984, 14, 163-170.

12. T. Mallouk and N. Bartlett, J. Chem. Soc., Chem. Commun., 1983, DOI: 10.1039/C39830000103, 103105.

13. I. Palchan, D. Davidov and H. Selig, J. Chem. Soc., Chem. Commun., 1983, DOI: 10.1039/C39830000657, 657-658.

14. C. Delabarre, K. Guérin, M. Dubois, J. Giraudet, Z. Fawal and A. Hamwi, J. Fluorine Chem., 2005, 126, 1078-1087.

15. Y. Sato, T. Kume, R. Hagiwara and Y. Ito, Carbon, 2003, 41, 351-357.

16. J. Giraudet, M. Dubois, K. Guérin, C. Delabarre, A. Hamwi and F. Masin, J. Phys. Chem. B, 2007, 111, 14143-14151.

17. A. Hamwi, J. Phys. Chem. Solids, 1996, 57, 677-688.

18. A. Hamwi, M. Daoud and J. C. Cousseins, Synth. Met., 1988, 26, 89-98.

19. Y. Sato, K. Itoh, R. Hagiwara, T. Fukunaga and Y. Ito, Carbon, 2004, 42, 3243-3249.

20. M. Murakami, K. Matsumoto, R. Hagiwara and Y. Matsuo, Carbon, 2018, 138, 179-187.

21. T. Nakajima, V. Gupta, Y. Ohzawa, H. Iwata, A. Tressaud and E. Durand, J. Fluorine Chem., 2002, 114, 209-214.

22. J. Li, K. Naga, Y. Ohzawa, T. Nakajima, A. I. Shames and A. M. Panich, J. Fluorine Chem., 2005, 126, 
265-273.

23. M.-J. Jung, J. W. Kim, J. S. Im, S.-J. Park and Y.-S. Lee, J. Ind. Eng. Chem., 2009, 15, 410-414.

24. O. Jankovský, P. Šimek, D. Sedmidubský, S. Matějková, Z. Janoušek, F. Šembera, M. Pumera and Z. Sofer, RSC Adv., 2014, 4, 1378-1387.

25. T. Nakajima and Y. Matsuo, Carbon, 1994, 32, 469-475.

26. T. Nakajima, A. Mabuchi and R. Hagiwara, Carbon, 1988, 26, 357-361.

27. Z. Wang, J. Wang, Z. Li, P. Gong, X. Liu, L. Zhang, J. Ren, H. Wang and S. Yang, Carbon, 2012, 50, 5403-5410.

28. L. Pu, Y. Ma, W. Zhang, H. Hu, Y. Zhou, Q. Wang and C. Pei, RSC Adv., 2013, 3, 3881-3884.

29. A. Hamwi and I. Al Saleh, J. Power Sources, 1994, 48, 311-325.

30. X. Gao and X. Tang, Carbon, 2014, 76, 133-140.

31. A. Hamwi, I. Al Saleh, D. Djurado and J. C. Cousseins, Mater. Sci. Forum, 1992, 91-93, 245-249.

32. T. Szabó, O. Berkesi and I. Dékány, Carbon, 2005, 43, 3186-3189.

33. W. C. Smith, Angew. Chem. Int. Ed., 1962, 1, 467-475.

34. W. R. Hasek, W. C. Smith and V. A. Engelhardt, J. Am. Chem. Soc., 1960, 82, 543-551.

35. W. J. Middleton, J. Org. Chem., 1975, 40, 574-578.

36. C. W. Tullock, F. S. Fawcett, W. C. Smith and D. D. Coffman, J. Am. Chem. Soc., 1960, 82, 539-542.

37. H. L. Poh, Z. Sofer, K. Klímová and M. Pumera, J. Mater. Chem. C, 2014, 2, 5198-5207.

38. H.-K. Jeong, Y. P. Lee, M. H. Jin, E. S. Kim, J. J. Bae and Y. H. Lee, Chem. Phys. Lett., 2009, 470, 255258.

39. J. Kollonitsch, S. Marburg and L. M. Perkins, J. Org. Chem., 1979, 44, 771-777.

40. Y. M. Pustovit and V. P. Nazaretian, J. Fluorine Chem., 1991, 55, 29-36.

41. $\quad$ K. Matsumoto and R. Hagiwara, J. Fluorine Chem., 2010, 131, 805-808.

42. B. MBC, Ann. Chim. Phys., 1860, 59, 466-472.

43. D. Peters and R. Miethchen, J. Fluorine Chem., 1996, 79, 161-165.

44. S. Stankovich, R. D. Piner, X. Chen, N. Wu, S. T. Nguyen and R. S. Ruoff, J. Mater. Chem., 2006, 16, 155-158.

45. T. Szabó, O. Berkesi, P. Forgó, K. Josepovits, Y. Sanakis, D. Petridis and I. Dékány, Chem. Mater., 2006, 18, 2740-2749.

46. $\quad$ C. V. Berney, J. Mol. Struct., 1972, 12, 87-97.

47. R. L. Redington and C. V. Berney, J. Chem. Phys., 1965, 43, 2020-2026.

48. K. Baum, J. Am. Chem. Soc., 1969, 91, 4594-4594.

49. P. L. Coe, L. D. Proctor, J. A. Martin and W. A. Thomas, J. Fluorine Chem., 1992, 58, 87-92.

50. $\quad$ K. C. Hodges, D. Schomburg, J. V. Weiss and R. Schmutzler, J. Am. Chem. Soc., 1977, 99, 6096-6097.

51. G. E. Wilson and B. A. Belkind, J. Am. Chem. Soc., 1978, 100, 8124-8130.

52. Q. Liu, Z. Wu, J. Xu, Y. Lu, H. Li and X. Zeng, J. Phys. Chem. A, 2017, 121, 3818-3825.

53. J. T. Goettel, N. Kostiuk and M. Gerken, Angew. Chem. Int. Ed., 2013, 52, 8037-8040.

54. D. W. Lee, L. De Los Santos V, J. W. Seo, L. L. Felix, A. Bustamante D, J. M. Cole and C. H. W. Barnes, 
J. Phys. Chem. B, 2010, 114, 5723-5728.

55. S. Stankovich, D. A. Dikin, R. D. Piner, K. A. Kohlhaas, A. Kleinhammes, Y. Jia, Y. Wu, S. T. Nguyen and R. S. Ruoff, Carbon, 2007, 45, 1558-1565.

56. O. Jankovský, V. Mazánek, K. Klímová, D. Sedmidubský, J. Kosina, M. Pumera and Z. Sofer, Chemistry - A European Journal, 2016, 22, 17696-17703.

57. Y. Sato, H. Watano, R. Hagiwara and Y. Ito, Carbon, 2006, 44, 664-670.

58. A. M. Panich, Synth. Met., 1999, 100, 169-185.

59. D. W. Boukhvalov and M. I. Katsnelson, J. Am. Chem. Soc., 2008, 130, 10697-10701.

60. N. V. Medhekar, A. Ramasubramaniam, R. S. Ruoff and V. B. Shenoy, ACS Nano, 2010, 4, 2300-2306. 